\title{
Autores USTA
}

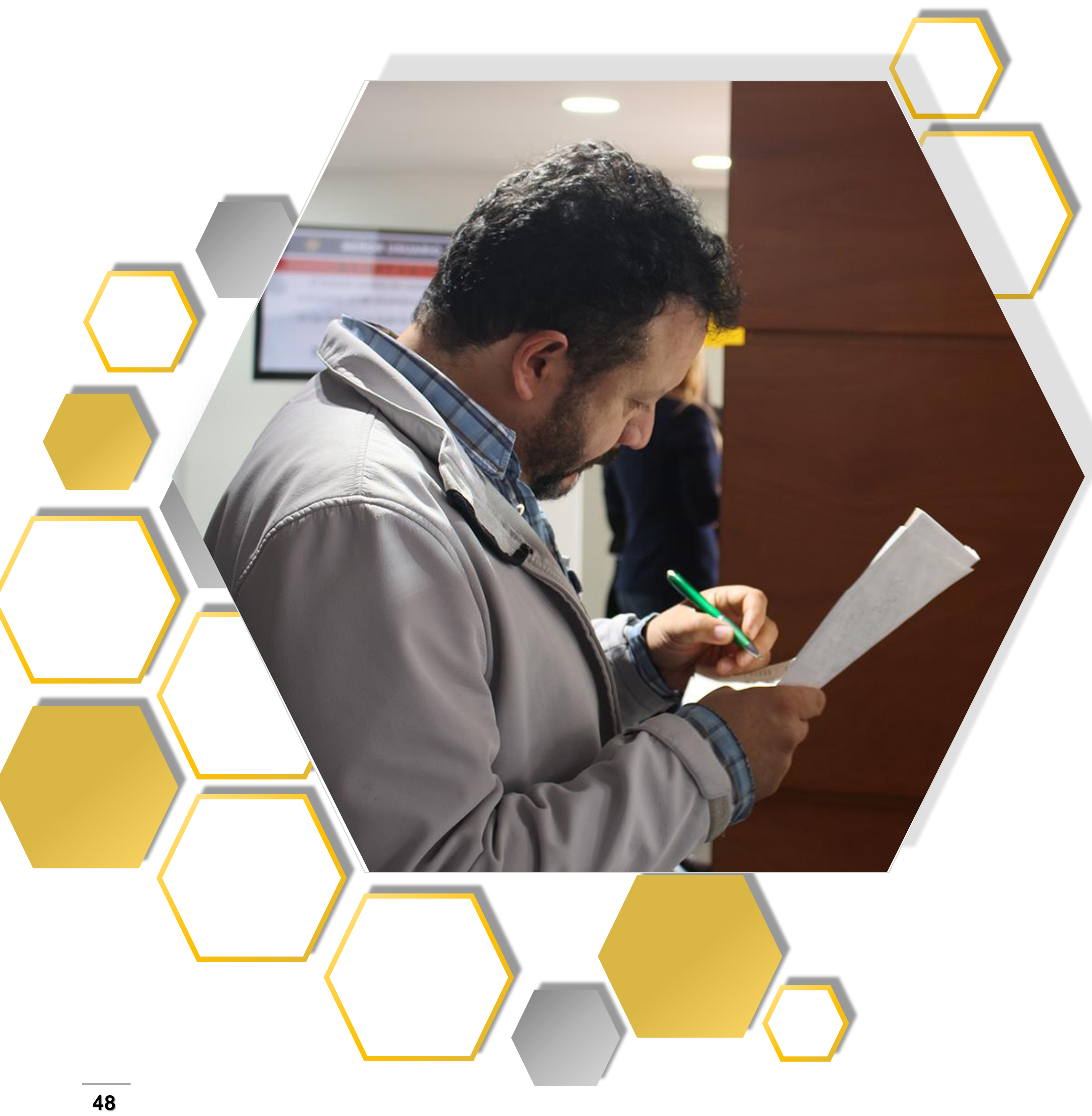




\section{Autores}

Google Académico o Google Scholar se ha convertido en la principal fuente con consulta de académicos e investigadores del mundo, respondiendo a grandes volúmenes de información en diferentes áreas de conocimiento, idiomas y fuentes documentales de fácil acceso (Falagas, Pitsouni, Malietzis, \&amp; Pappas, 2008; Meho \&amp; Yang, 2007) . En consecuencia, el análisis de los autores en esta plataforma con perfil público y filiación institucional de la Universidad Santo Tomás (Colombia) en el periodo 2002-2018 permitió identificar el comportamiento de sus indicadores bibliométricos de autor como producción, citación, índice H e índice H5.

En total se identificaron 485 autores USTA en Google Académico donde se incluyen docentes, estudiantes, investigadores, administrativos, directivos, entre otros. El promedio de citas por autor es 63,2 por año a causa de las 13.084 (prom.) citas por año del autor Hanwen Zhang, lo que lo convierte en uno de los autores más importante del mundo en estadística, series de tiempo y estadística bayesiana con índice $\mathrm{H}$ 202. Sin tener en cuenta las métricas de Hanwen el promedio anual de citas los autores USTA es 4,8. Por otra parte, se identifica un incremento constante (4300 prom.) de citas desde 2010 con un pico superior en 2018 (36474 citas), esto refleja el impacto de las estrategias institucionales implementadas desde la Vicerrectoría Académica, Dirección de Innovación e Innovación Sede Principal, CRAI USTA y Observatorio de Cienciometría USTA que incluye la implementación del repositorio institucional y el ajuste de los metadatos al Sistema Nacional de Ciencia, Tecnología e Innovación (Corchuelo-Rodriguez, 2018) , el uso del Open Journal Systems (OJS), las membresías en ORCID, DOAJ, entre otros. Finalmente. el índice H5 el promedio de los autores USTA es 174,9 en el periodo 2014-2018.

En lo relacionado con los indicadores de producción en total los autores USTA registran 7365 con un promedio de 15,15 por autor. El top 10 de los autores con más publicaciones es liderado por Hanwen Zhang con 1000 documentos. De igual manera, se identificaron los productos con mayor cantidad de citas siendo el artículo "observation of a new practicle in the search for the standard model higgs boson with the Atlas detector at the LHC", publicado en 2012, el artículo con más citas (16006). 


\section{Ficha técnica}
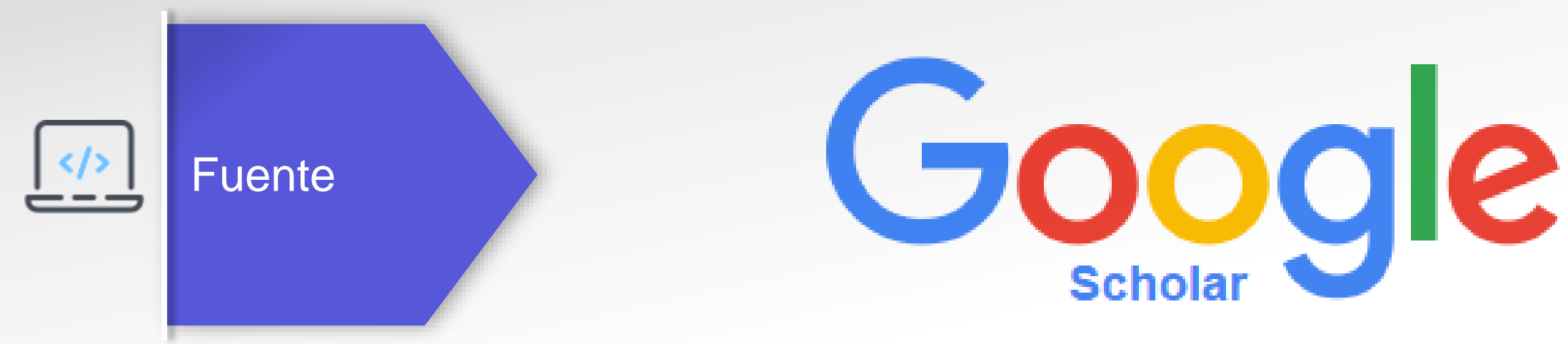

Autores con filiación "universidad santo tomas" OR "santo tomás university" OR "Univ Santo Tomas" OR "Universidad Santo Tomás"

Harzing's Publish or Peris (POP), Microsoft Excel
Q.․․… Periodo de análisis 2002-2018

\section{DATOS USTA}

http://observatoriocienciometria.usta.edu.co/index.php/metricas -usta/autores-y-grupos-de-investigacion

\section{DATOS ABIERTOS:}

DOI: $10.5281 /$ zenodo.3235623

Fecha de consulta: 04/02/2019 


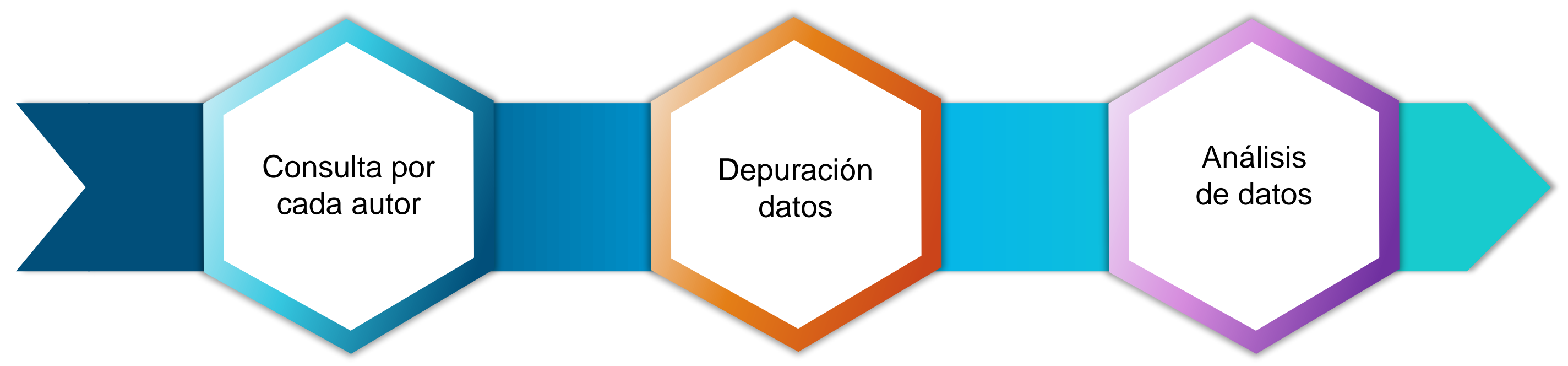

\section{Resultados}

485

Autores

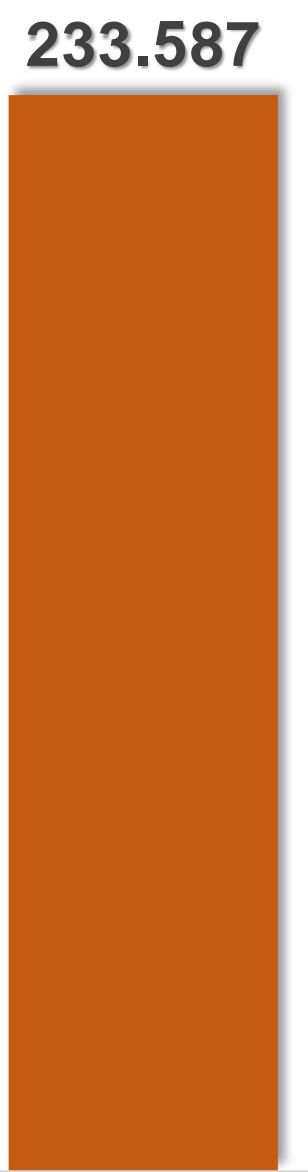

Citas
2

Indice H5 (promedio)

Gráfica 29. Citas e índice H de autores USTA en Google Académico 


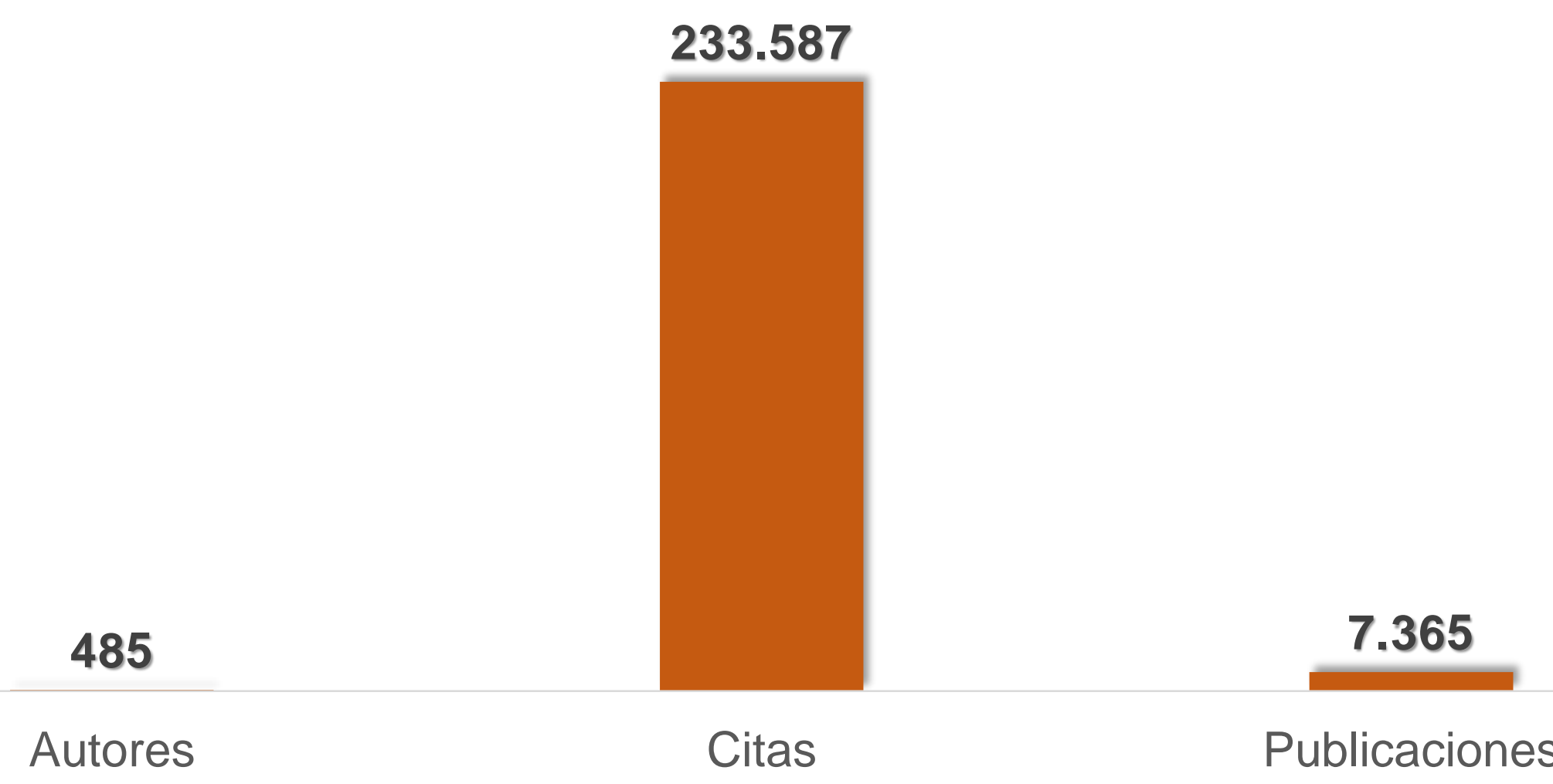

Gráfica 30. Citas y publicaciones de autores USTA en Google Académico

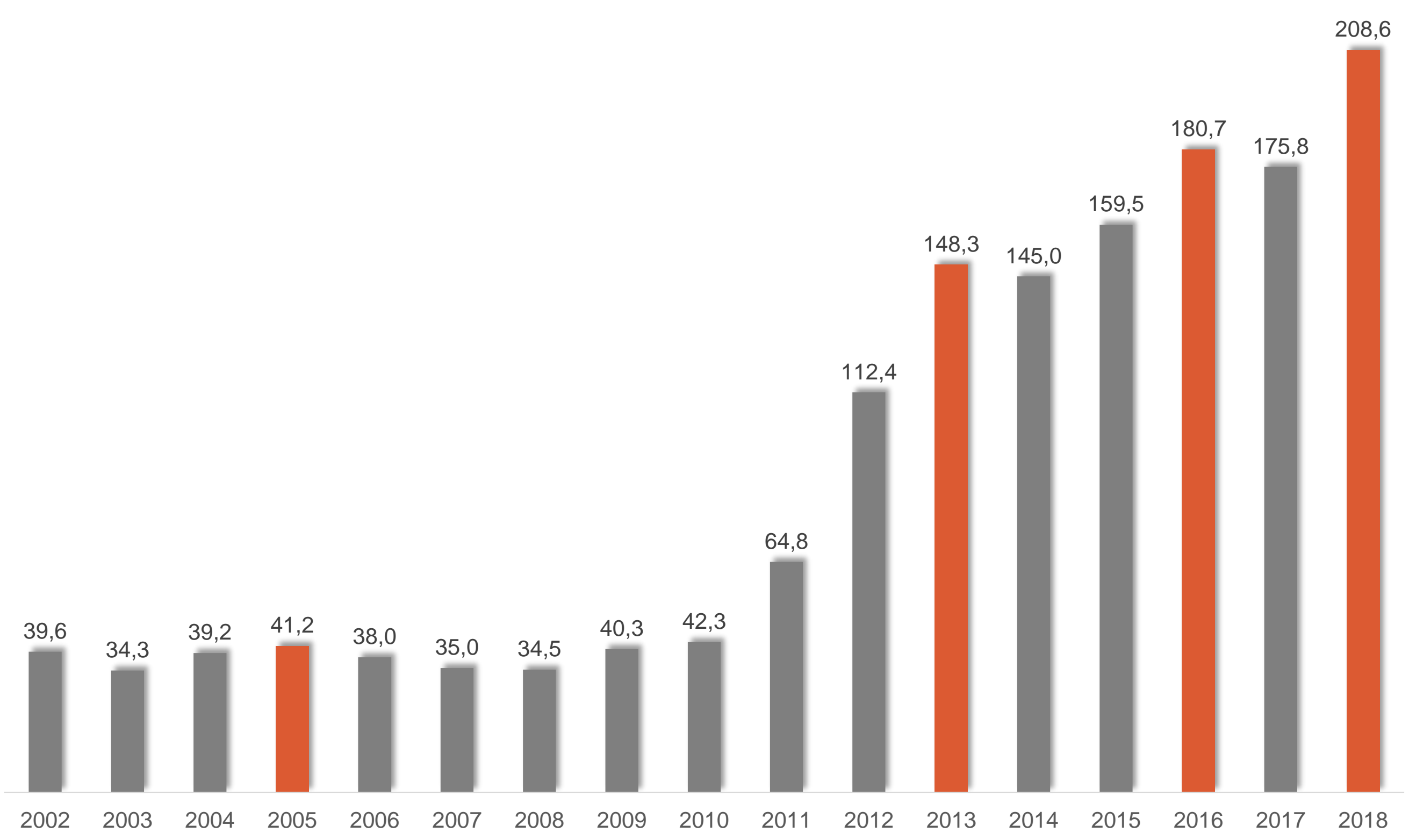

Gráfica 31. Promedio de citas de Autores USTA en Google Académico por año 
Top 10 de los autores con más publicaciones Google académico

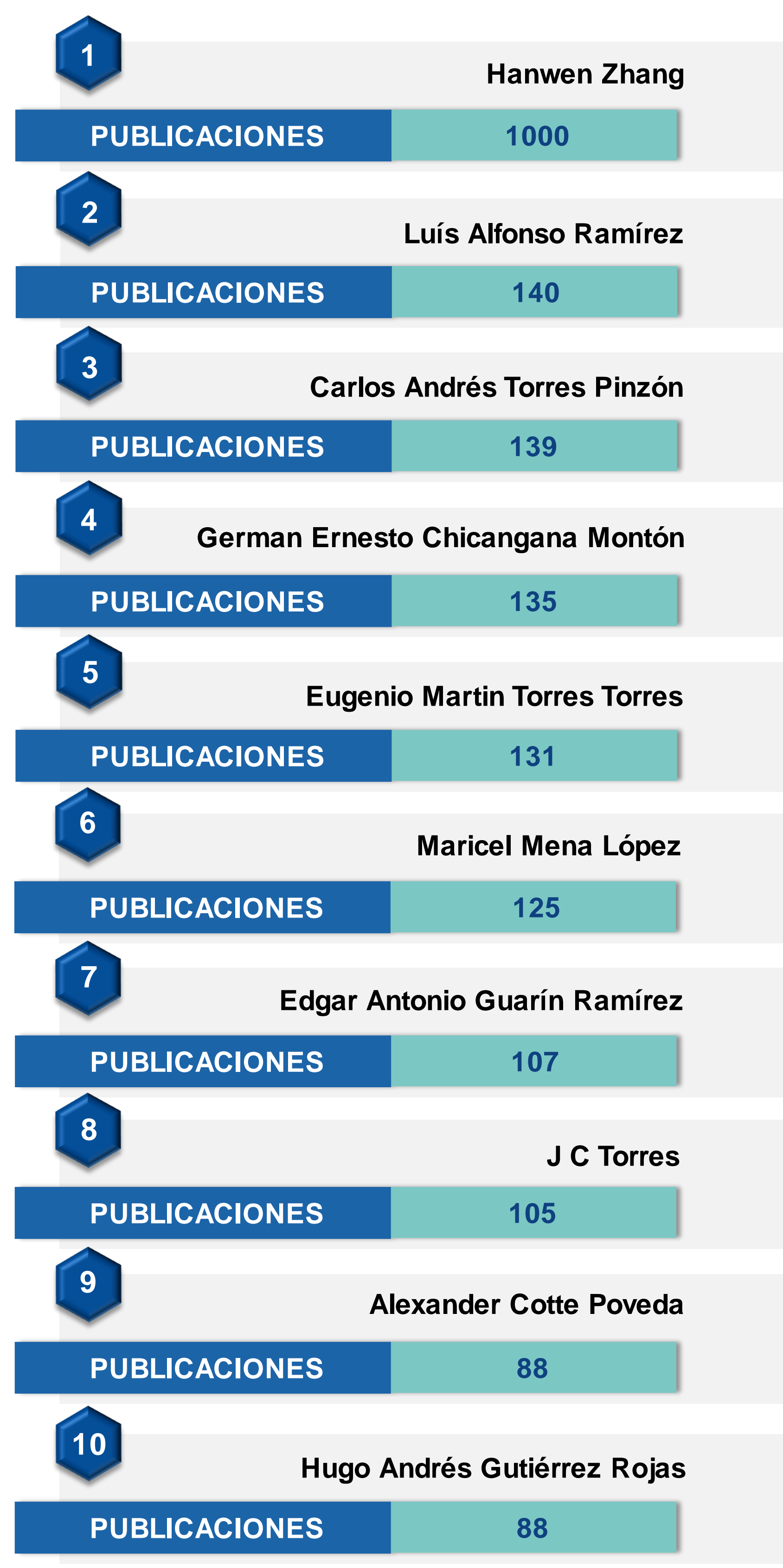




\section{Top 10 de los autores con más citas en Google académico}
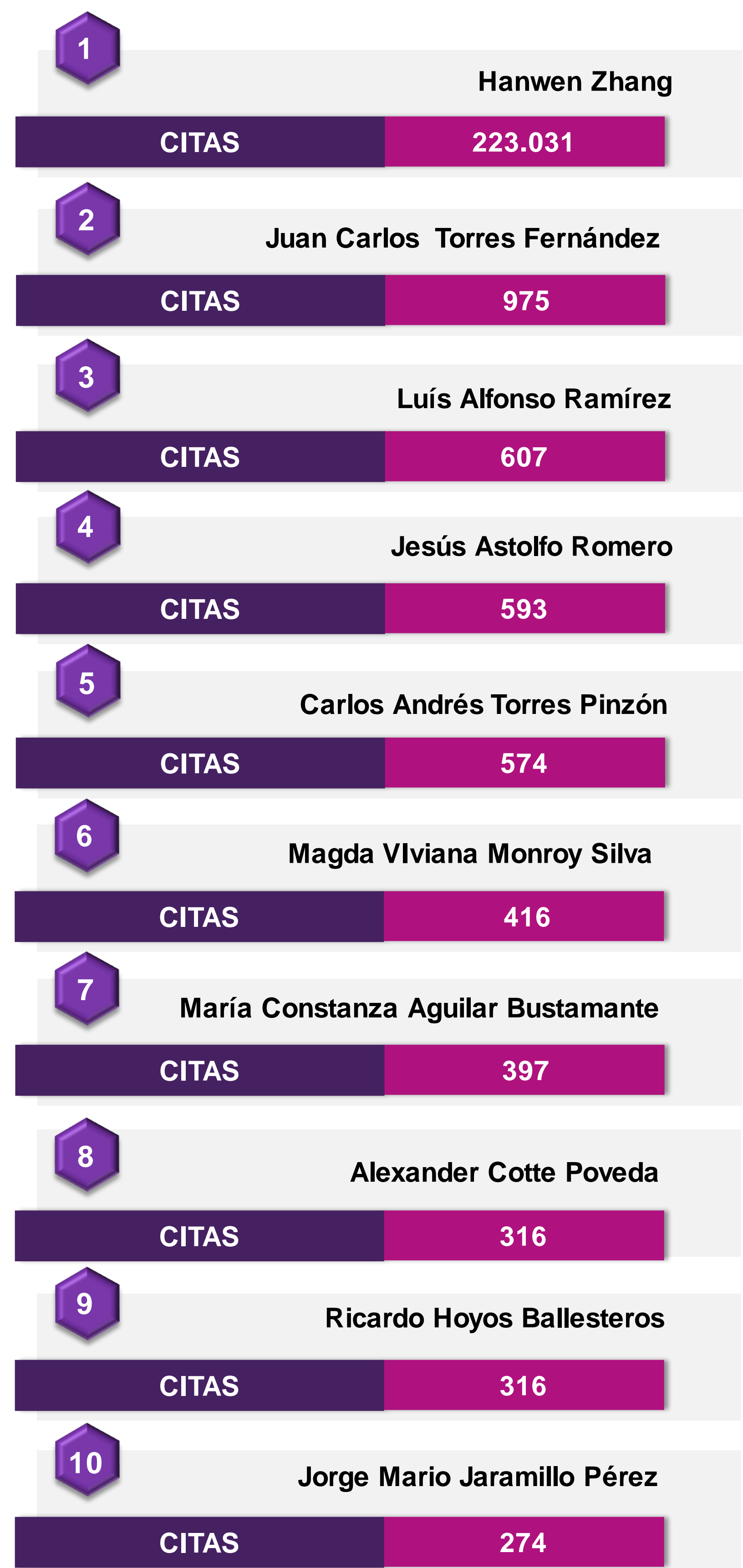


\section{Top 10 de los autores con más Índice H en Google académico}

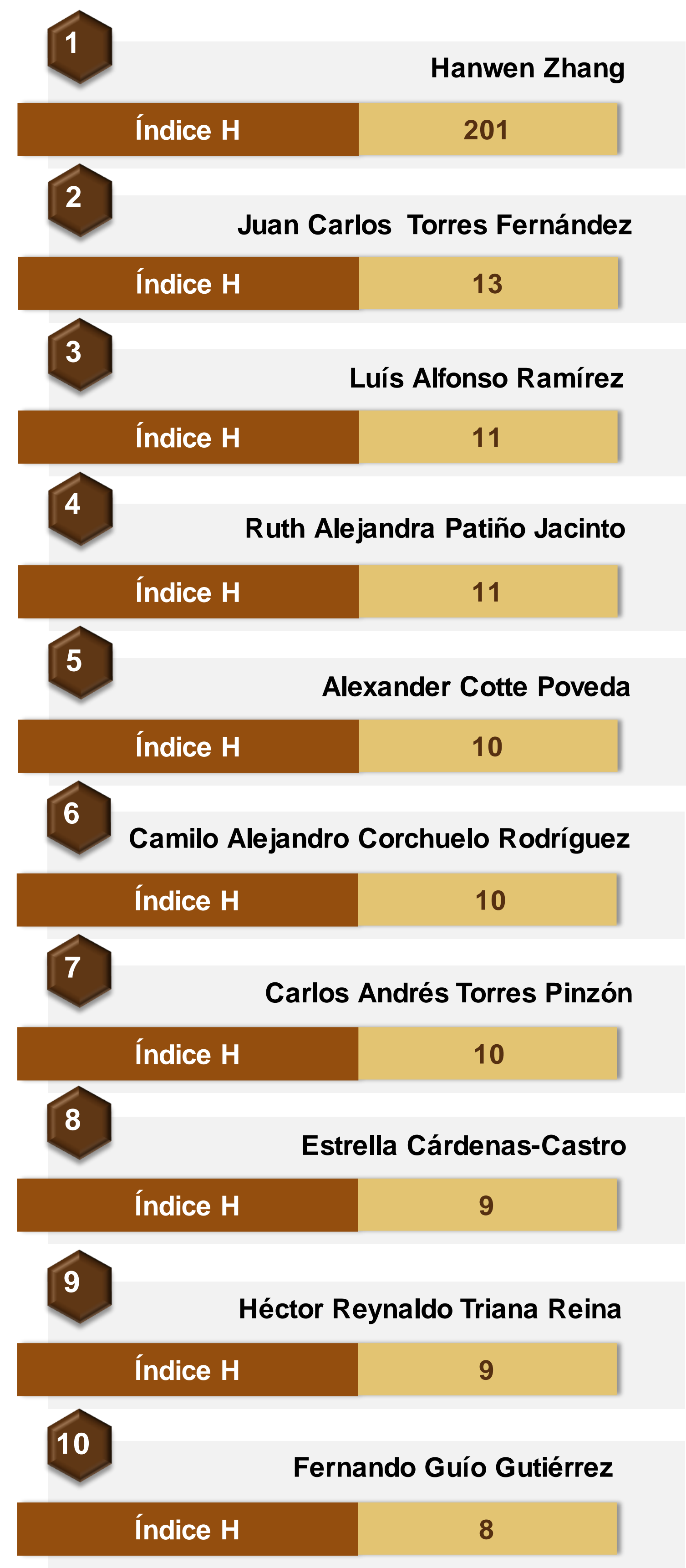




\section{Top 10 de las publicaciones de Autores USTA con más citas en Google académico}

1

Physics Letters B

Hanwen Zhang

CITAS 16,006

AÑO 2012

2

Water, Air, and Soil Pollution 205 (1-4)

CITAS 326

AÑO 2010

3

Diversitas: perspectivas en psicología
CITAS 161
AÑO 2006

Ecoe ediciones

AÑO 2000

5

Universidad piloto de Colombia

CITAS 147

AÑO 2013

6

PAIN $B$

CITAS 135

AÑO 2013
CITAS 161

Observation of a new particle in the search for the Standard Model Higgs boson with the ATLAS detector at the LHC

Juan Carlos Torres Fernández Advanced oxidation processes for wastewater treatment: state of the art

Maria Constanza Aguilar Bustamante

Panorama sobre los estudios de clima organizacional en Bogotá, Colombia (1994-2005)

Ricardo Hoyos Ballesteros

Plan de marketing: diseño, implementación y control

Mónica Eliana García Gil

La investigación en ciencias sociales: estrategias de investigación

Magda VIviana Monroy Silva

Disabling musculoskeletal pain in working populations: is it the job, the person, or the culture?

Carlos Andrés Torres Pinzón

Ciudad informal colombiana: barrios

construidos por la gente
CITAS 116
AÑO 2011

8

BioMed research international

Marco Antonio Velasco Peña
CITAS 109
AÑO 2015

Design, materials, and mechanobiology of biodegradable scaffolds for bone tissue engineering

9 Diversitas: perspectivas en psicología

Jorge Mario Jaramillo Perez

Comprensión del significado desde Vygotsky,
Bruner y Gergen

Comprensión del significado desde Vygotsky,
Bruner y Gergen
CITAS 108
AÑO 2010

10

La economía política

Jairo Bautista

CITAS 88

AÑO 2009 